\title{
Fracture behavior of random distributed short tungsten fiber-reinforced tungsten composites
}

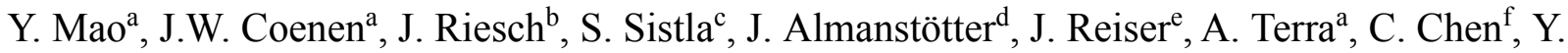

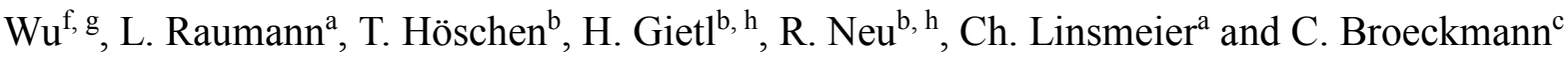

${ }^{a}$ Forschungszentrum Jülich GmbH, Institut für Energie- und Klimaforschung - Plasmaphysik, Partner in the Trilateral Euregio Cluster, 52425 Jülich, Germany

${ }^{b}$ Max-Planck-Institut für Plasmaphysik, 85748 Garching b. München, Germany

${ }^{c}$ Institut für Werkstoffanwendungen im Maschinenbau (IWM), RWTH Aachen University, 52062 Aachen, Germany

${ }^{d}$ OSRAM GmbH, SP PRE PLM DMET, Mittelstetter Weg 2, 86830 Schwabmünchen, Germany ${ }^{e}$ Karlsruhe Institute of Technology, Institute for Applied Materials, 76344 Eggenstein-

Leopoldshafen, Germany

${ }^{f}$ School of Materials Science and Engineering, Hefei University of Technology, Hefei 230009, China

${ }^{g}$ China International S\&T Cooperation Base for Advanced Energy and Environmental Materials, Hefei 230009, China

\footnotetext{
${ }^{h}$ Technische Universität München, Boltzmannstr. 15, 85748 Garching, Germany Corresponding author: y.mao@fz-juelich.de (Yiran.Mao)
}

\begin{abstract}
In future fusion reactors, tungsten is considered as the main candidate material for plasma-facing components. However, the intrinsic brittleness of tungsten is of great concern during operation. To overcome this drawback, tungsten fiber-reinforced tungsten composites $\left(\mathrm{W}_{\mathrm{f}} / \mathrm{W}\right)$ are being
\end{abstract}


developed relying on extrinsic toughening principles. Tungsten (W) fibers with extremely high tensile strength and ductility are used to reinforce a tungsten matrix.

In this work, field assisted sintering technology (FAST) is used to produce $\mathrm{W}_{\mathrm{f}} / \mathrm{W}$ material. Mechanical characterizations including Charpy impact and 3-point bending tests are performed. Based on the 3-point bending test results, the $\mathrm{W}_{\mathrm{f}} / \mathrm{W}$ materials can facilitate a promising pseudoductile behavior even at room temperature, similar to fiber reinforced ceramic composites. Fracture energy density and fracture toughness together with the crack-resistance curves (R-curves) are measured. Compared to conventional pure tungsten, $\mathrm{W}_{\mathrm{f}} / \mathrm{W}$ shows significant improvement in fracture toughness.

Keywords: Tungsten; Composite; Fracture; Mechanical testing

\section{Introduction}

For future fusion reactors, plasma facing components will face severe challenges and materials with advanced mechanical and thermal properties are required for this application [1,2]. Tungsten (W) is currently the main candidate material for this application as it is resilient against erosion, has the highest melting point of any metal and shows rather benign behavior under neutron irradiation [3]. However, a major concern when using pure tungsten is its intrinsic brittleness, with respect to the fusion environment with high transient heat loads and neutron irradiation. Cracks will likely form and lead to component failure due to material brittleness [4]. To overcome this drawback, tungsten fiber-reinforced tungsten $\left(\mathrm{W}_{\mathrm{f}} / \mathrm{W}\right)$ composites are being developed. Relying on extrinsic toughening principles, even with brittle fibers and matrix, this material shows improved tolerance towards cracking and damage compared to conventional tungsten [5-10]. 
Extensive studies have been performed based on $\mathrm{W}_{\mathrm{f}} / \mathrm{W}$ produced by chemical vapor deposition (CVD) process [10-13]. However, industrially, powder metallurgical (PM) processes are the main path to tungsten materials. Therefore, the development of a PM route is important for large-scale production of tungsten composites.

Recently, a process using field assisted sintering technology (FAST) has been established to produce $\mathrm{W}_{\mathrm{f}} / \mathrm{W}$ bulk material $[5-7,14]$. FAST is a low voltage, pulsed direct current (DC) activated, pressure-assisted sintering and synthesis technique. This method can be used to synthesize new compounds and/or to densify materials in single step $[15,16]$.

For $\mathrm{CVD}$ produced $\mathrm{W}_{\mathrm{f}} / \mathrm{W}$, long fibers are normally used to reinforce the tungsten matrix. However, as it is technically difficult to introduce aligned long fibers into the bulk material in the FAST process. Therefore, short fibers with random distribution are used to realize the reinforcement [5]. This different fiber structure could lead to a significant difference with respect to the fracture behavior compared to $\mathrm{CVD}$ produced $\mathrm{W}_{\mathrm{f} / \mathrm{W}} \mathrm{W}$. Therefore, a clear understanding of the fracture behavior of the random fiber $\mathrm{W}_{\mathrm{f}} / \mathrm{W}$ is necessary. An analysis of $\mathrm{W}_{\mathrm{f}} / \mathrm{W}$ material regarding the fracture energy and fracture toughness is required to allow a comparison with pure tungsten material. In general, similar to the ceramic fiber reinforced composites, a relatively weak interface between the fiber and the matrix is considered to be beneficial to achieve pseudo-ductility $[5,17$, $18]$.

This work deals with the fracture behavior and fracture resistance of randomly distributed short fiber $\mathrm{W}_{\mathrm{f}} / \mathrm{W}$. A Charpy impact test is used to measure the impact energy. A 3-point bending system allowing an in-situ observation of the crack opening process is applied. Based on the quantitatively measured force displacement curve, the fracture energy and fracture toughness together with the 
fracture resistance curves (R-curves) have been calculated, indicating an increased defect tolerance.

\section{Experiments}

\subsection{Composite manufacturing}

The raw materials for the $\mathrm{W}_{\mathrm{f}} / \mathrm{W}$ composite production are pure tungsten powders (provided by OSRAM GmbH) with $5 \mu \mathrm{m}$ average particle size and potassium doped short tungsten fibers (provided by OSRAM GmbH) with $2.4 \mathrm{~mm}$ length and $0.15 \mathrm{~mm}$ diameter. The tungsten fibers are produced by a drawing process and then cut into the required length. Relying on the elongated drawn grain structure, the tungsten fibers are ductile with extremely high tensile strength $(\sim 3000$ MPa) [19]. The potassium doping provides an improved high temperature stability [20].

Before the consolidation process, the tungsten fibers are coated with yttrium oxide as interface material. The coating is prepared by a 4 steps process with magnetron sputtering similar to [5]. The coating thickness is $\sim 2 \mu \mathrm{m}$. Then the coated fibers are mixed with the tungsten powders by manual shaking in a vessel with a fiber mass fraction of $30 \%$. The mixture is then poured into the FAST graphite mold (Figure 1). The consolidation process is performed in a FAST system (HP D 25-2) from "FCT Systeme GmbH".

A schematic drawing of the sintering mold systems is shown in Figure 1. Two different types of tool design are used:

a) Graphite sheets are placed between punch and mixture, aiming to reduce the damage of the punch surface and to facilitate easier sample removal after the FAST process (Figure 1 left).

b) Instead of graphite sheets, tungsten sheets are placed between punch and mixture, aiming to reduce the carbon contamination. 
Previous studies $[6,21]$ revealed that, when the sample is sintered with a graphite foil, the tungsten fibers become brittle after sintering due to carbon contamination. By replacing the graphite foil with pure tungsten foil, this undesirable outcome is avoided.

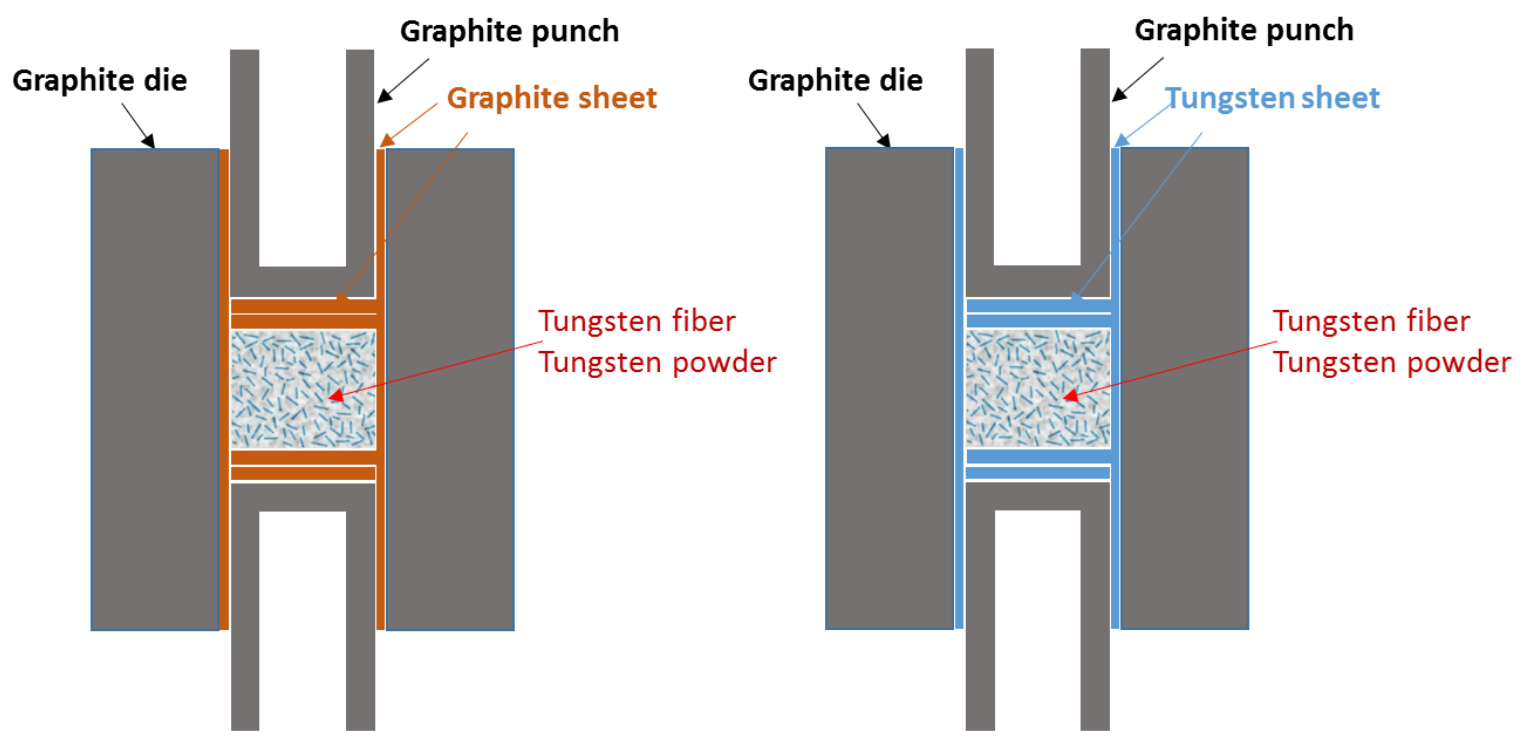

Figure 1 Two FAST mold systems for $\mathrm{W}_{\mathrm{f}} / \mathrm{W}$ production
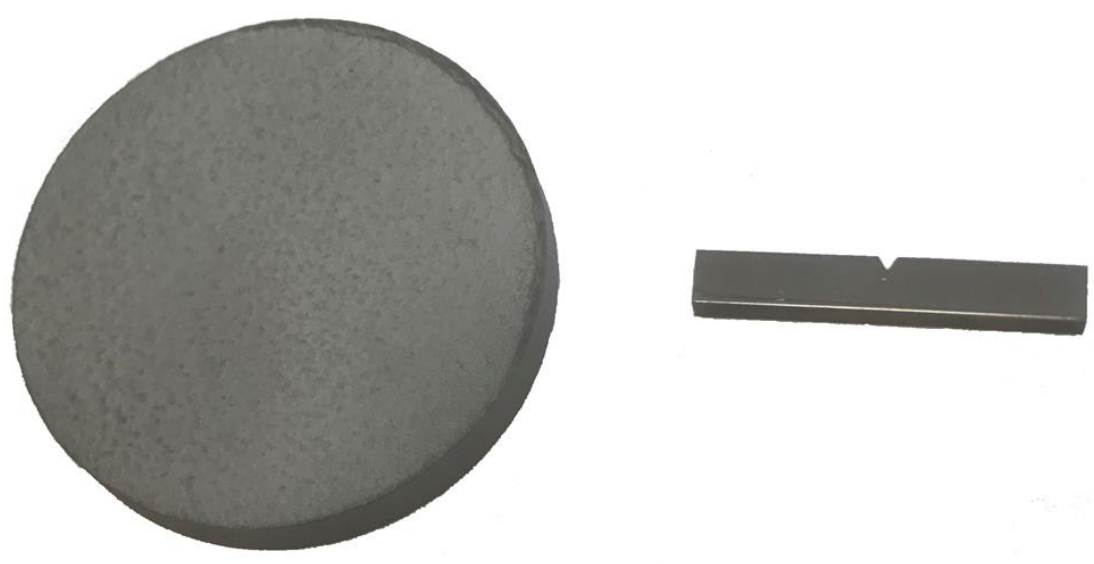

Figure 2 left: typical sample after sintering; right: the mechanical testing sample

During the consolidation process, a constant heating rate of $200{ }^{\circ} \mathrm{C} / \mathrm{min}$ up to a temperature of $1900{ }^{\circ} \mathrm{C}$ (the temperature is measured at the bottom of the semi-hollow punch), with 4 minutes holding time and a constant pressure of $60 \mathrm{MPa}$ is applied [22-24]. The average cooling rate from 
$1900^{\circ} \mathrm{C}$ to $400^{\circ} \mathrm{C}$ is $\sim 375^{\circ} \mathrm{C} / \mathrm{min}$. The sintering is performed in vacuum below $0.1 \mathrm{mbar}$. As result, coin shaped samples ( $40 \mathrm{~mm}$ diameter and $\sim 5 \mathrm{~mm}$ height) are produced (Figure 2 left). The relative density of the samples after sintering is around $94 \%$ according to the density measurement using the Archimedes principle. After the sintering process, the microstructure of the $\mathrm{W}_{\mathrm{f}} / \mathrm{W}$ is studied by a LEO 982 scanning electron microscope (SEM).
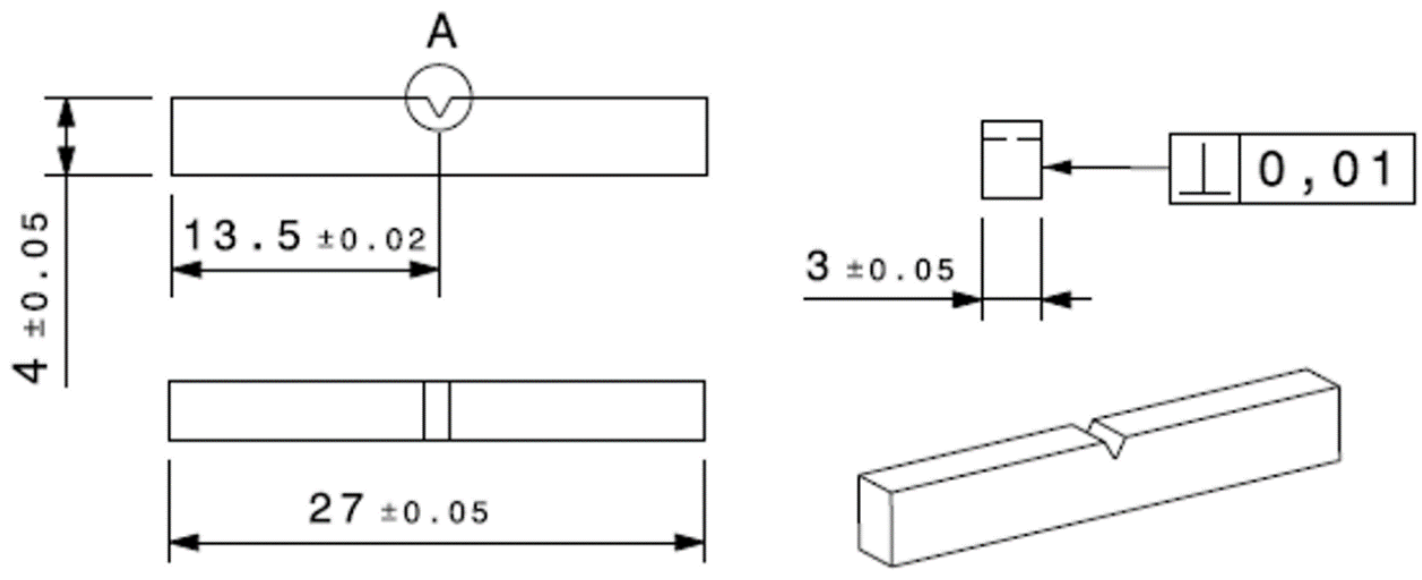

Figure 3 mechanical testing sample geometry (based on [25])

Mechanical testing (Charpy impact and 3-point bending) samples are manufactured based on the EU standards DIN EN ISO 148-1 and 14556: 2006-10 [25]. According to this standard the small size specimens have the following dimensions (KLST geometry, Figure 3) [26]: $3 \mathrm{~mm} \times 4 \mathrm{~mm} x$ $27 \mathrm{~mm}, 22 \mathrm{~mm}$ span, $1 \mathrm{~mm}$ V-notch depth, $0.1 \mathrm{~mm}$ notch root radius. The sample dimension is shown in Figure 3 and typical real sample is shown in Figure 2 right. All samples are shaped by EDM without further surface and notch modification.

\subsection{Charpy impact test}

To measure the impact energy of the $\mathrm{W}_{\mathrm{f}} / \mathrm{W}$, a Charpy impact test is performed. Charpy impact testing involves striking a standard notched specimen with a controlled weight instrument tup from 
a defined height. The Charpy impact test device is designed in a drop-weight style. During the test, the energy absorbed by the impact can be determined as impact energy $\left(K_{v}\right)$.It shows whether the material can be classified as being either brittle or ductile. In addition, the appearance of a fracture surface also gives information about the type of fracture that has occurred.

To analyze the temperature influence on the impact energy, Charpy impact tests are performed at room temperature and $1000{ }^{\circ} \mathrm{C}$. The specimen is heated together with the support which allows for easy and precise test temperature control. To minimize the oxidation of the tungsten samples, the tests were performed in vacuum $\left(\sim 10^{-3} \mathrm{mbar}\right)$. The drop-weight is catapulted out of the furnace immediately after the test by a spring device, and is then arrested [25].

\subsection{In-situ 3-point bending test}

Charpy impact test is a high-deformation-rate method that could have a strong influence on the testing results [27]. For comparison, a 3-point bending test with much lower displacement rate is also applied. The sample dimension is shown in Figure 3. The bending test is performed using a universal testing device (TIRAtest 2820, Nr. R050/01, TIRA GmbH). During the bending test (1 $\mu \mathrm{m} / \mathrm{s}$ testing speed), an optical camera system (DU657M Toshiba) is used to track crack behavior and absolute sample movement. One typical tracking image during the experiment is shown in Figure 4 left. The sample displacement in this test is defined as the vertical movement of the sample relative to the reference stage. At the same time the corresponding force is also recorded. As result, a quantitatively measured force-displacement curve can be then determined.

Based on the force-displacement curves, the fracture energy is calculated by integrating the area below the curves, showing the energy consumption during fracture (Figure 4 right). In this calculation, when the force drops below $50 \mathrm{~N}$, the test is considered to be finished. 


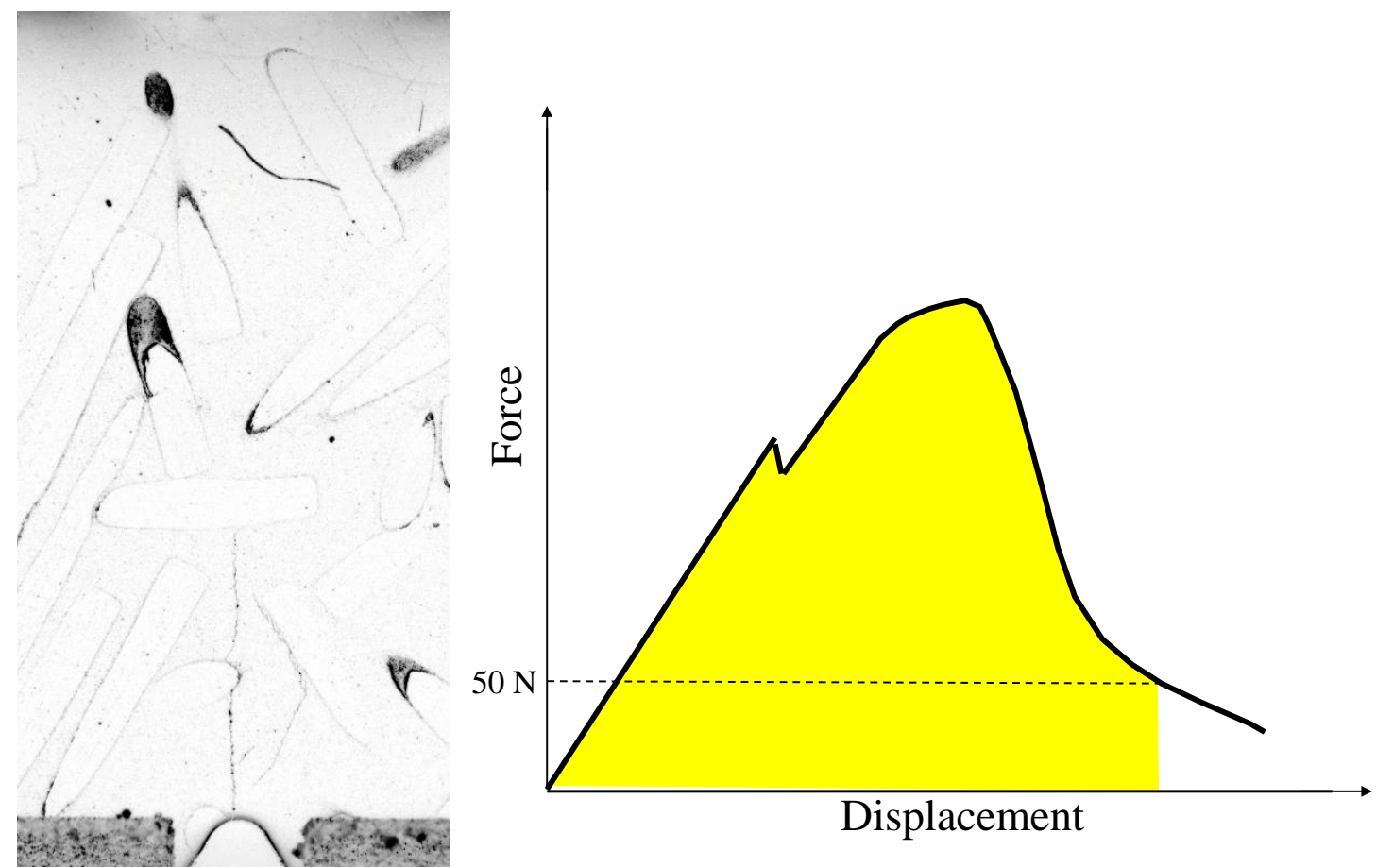

Figure 4 left: image from tracking camera during the bending test; right: measured force displacement curve during the bending test and the fracture energy calculation based on the integration below the curve

Fracture toughness $\left(\mathrm{K}_{\mathrm{q}}\right)$ is determined based on ASTM E399 standard by combining the stable crack growth length and the corresponding load during the test:

$$
K_{q}=\frac{P \cdot S}{B \cdot W^{3 / 2}} \cdot f\left(a_{f} / W\right)
$$

Where $P$ is the maximum load during stable crack growing, $S$ is the distance between the support pins, $B$ is the sample width, $W$ is the sample thickness, $a_{f}$ is the stable crack length which equals to the pre-notch length plus the crack extension length, the function $f\left(a_{f} / W\right)$ is described in ASTM E399:

$$
f\left(\frac{a_{f}}{W}\right)=\frac{3\left(\frac{a_{f}}{W}\right)^{\frac{1}{2}}\left\{1.99-\left(\frac{a_{f}}{W}\right)\left(1-\frac{a_{f}}{W}\right)\left(2.15-\frac{3.93 a_{f}}{W}+\frac{2.7 a_{f}{ }^{2}}{W^{2}}\right)\right\}}{2\left(1+\frac{2 a_{f}}{W}\right)\left(1-\frac{a_{f}}{W}\right)^{\frac{3}{2}}}
$$


Here, the maximum stable crack extension length is measured as the surface crack length based on the in-situ tracking image. The corresponding force is the maximum force before the unstable load drop.

The calculated fracture toughness defines the material resistance against crack opening. The $K_{q}$ value is equivalent to the critical stress intensity factor $\left(K_{I C}\right)$ only if all criteria given in the standard are fulfilled. Compared to E399 standard, in this work, the sample size is too small, and the notch is not fatigue prepared. What is more important, this standard is initially valid for homogeneous material instead of composite material. Therefore, in this work, only $K_{q}$ instead of the standard $K_{I c}$ is given as a first indication of the fracture toughness.

The fracture resistance curves (R-curve) are determined from the experimental data. These curves represent the fracture toughness $K_{q}$ for a given amount of crack extension length. In this work, for each sample, during the stable crack extension procedure, 6 time-points are picked in between. For each point, the $K_{q}$ value is calculated based on the force and crack length at the moment by using equation (1). The crack extension length is measured as the surface crack length based on the insitu tracking image, similar to the fracture toughness calculation.

Generally speaking, there are two different types of R-curve, a rising R-curve and a flat R-curve. A rising R-curve indicates that, for a further crack opening, the crack driving force needs to be increased, which hints towards defect tolerance. Typically, ductile materials [28] or composite materials with proper reinforcement exhibit a rising R-curve. For composite materials, it is created by fiber bridging causing mechanical interlocks.

The R-curve for an ideally brittle material is flat. For a further crack opening, the resistance remains constant because surface energy of the newly generated crystal surfaces is a fixed material 
property for a given orientation [29-31]. This means that if the driving force is higher than the resistance:

$$
G>K_{R}
$$

the material will exhibit unstable crack growth leading to a catastrophic failure.

For a high toughness material, not only the driving force needs to be higher than the resistance, but also the change in rate of driving force per crack extension should be larger than the slope of the R-curve [32].

$$
G>K_{R} \text { and } \frac{\partial G}{\partial a_{f}}>\frac{\partial K_{R}}{\partial a_{f}}
$$

Only then does unstable crack growth occur, which provides larger resilience against cracking.

During the 3-point bending test, four types of samples are tested, a) pure W produced by FAST process; b) $\mathrm{W}_{\mathrm{f}} / \mathrm{W}$ without an engineered interface; c) $\mathrm{W}_{\mathrm{f}} / \mathrm{W}$ with yttria interface produced with graphite sheets; d) $\mathrm{W}_{\mathrm{f}} / \mathrm{W}$ with yttria interface produced with tungsten sheets. For sample type a), b) and d), 2 samples are tested. For sample type c), 4 samples are studied.

\section{Results and discussion}

\subsection{Microstructure}

The typical microstructure is shown in Figure 5. This microstructure is similar to the results in previous studies $[5,7,14]$ : The randomly distributed fibers are visible. Between fiber and matrix, the yttrium oxide interface is still visible after sintering. However the layer also gets partially damaged due to the high temperature and pressure during the sintering process similar to the results in $[5,33]$. During the production process, the external pressure will deform the yttrium oxide 
interface as it can be seen in Fig. 5. After the sample production, there could be some residual stress in the interface region, forming mechanical interlock between fiber and matrix. Therefore, the interface strength is higher compared to smooth yttria interface in CVD produced $\mathrm{W}_{\mathrm{f}} / \mathrm{W}$ [34].

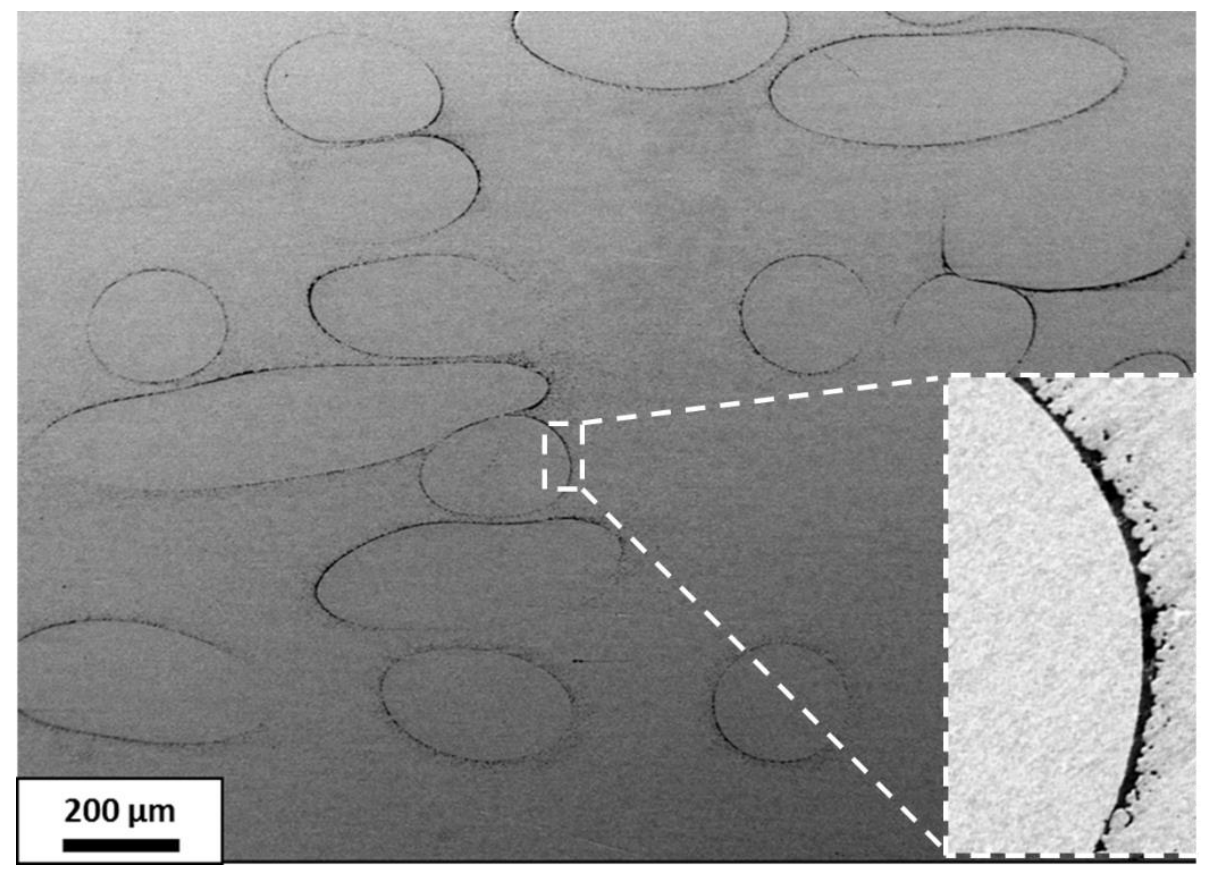

Figure 5 SEM image showing the typical microstructure of $\mathrm{W}_{\mathrm{f}} / \mathrm{W}$ material

\subsection{Charpy impact test}

The measured impact energies for different samples are shown in Table 1. All the samples are produce with graphite sheets (Figure 1 left). For each measuring parameter, one or two tests were carried out. The expression ' $\mathrm{W}_{\mathrm{f}} / \mathrm{W}$ without interface' denotes $\mathrm{W}_{\mathrm{f}} / \mathrm{W}$ samples without the yttria interface between fiber and matrix; ' $\mathrm{W}_{\mathrm{f}} / \mathrm{W}$ ' denotes for $\mathrm{W}_{\mathrm{f}} / \mathrm{W}$ with yttria interface.

The results in Table 1 show very low impact energies in all cases. The accuracy of this Charpy impact test is $1 \mathrm{~J}$. This means, all the tests cannot be accurately validated. The materials are too brittle under the high strain rate condition of the impact test. 
Table 1 Charpy impact energy of the pure tungsten and $\mathrm{W}_{\mathrm{f}} / \mathrm{W}$ material at different temperatures

\begin{tabular}{|c|c|c|c|c|c|c|}
\hline \multirow{2}{*}{$\begin{array}{c}\text { Sample/ } \\
\text { impact } \\
\text { energy (J) }\end{array}$} & \multicolumn{2}{|c|}{ Pure tungsten } & \multicolumn{2}{c|}{$\mathrm{W}_{\mathrm{f}} / \mathrm{W}$ without interface } & \multicolumn{2}{c|}{$\mathrm{W}_{\mathrm{f}} / \mathrm{W}$} \\
\cline { 2 - 7 } & Test Nr. 1 & Test Nr. 2 & Test Nr. 1 & Test Nr. 2 & Test Nr. 1 & Test Nr. 2 \\
\hline RT & 0,04 & 0,07 & 0,08 & 0,08 & 0,08 & 0,07 \\
\hline 1000 & 0,1 & - & 0,31 & - & 0,39 & 0,49 \\
\hline
\end{tabular}

Figure 6 shows the fracture surface of the $\mathrm{W}_{\mathrm{f}} / \mathrm{W}$ after testing at $\mathrm{RT}$ and $1000{ }^{\circ} \mathrm{C}$. At both temperatures the tungsten matrix shows brittle intergranular fracture behavior. In terms of tungsten fiber, for the sample tested at RT, the fiber fracture surface represents a typical river-like pattern that is typical for a transgranular cleavage fracture. On the other hand, at $1000{ }^{\circ} \mathrm{C}$, a knife edge shape pattern together with a necking effect is visible on the tungsten fibers. This is a typical fracture surface for the ductile tungsten fiber $[10,19]$.
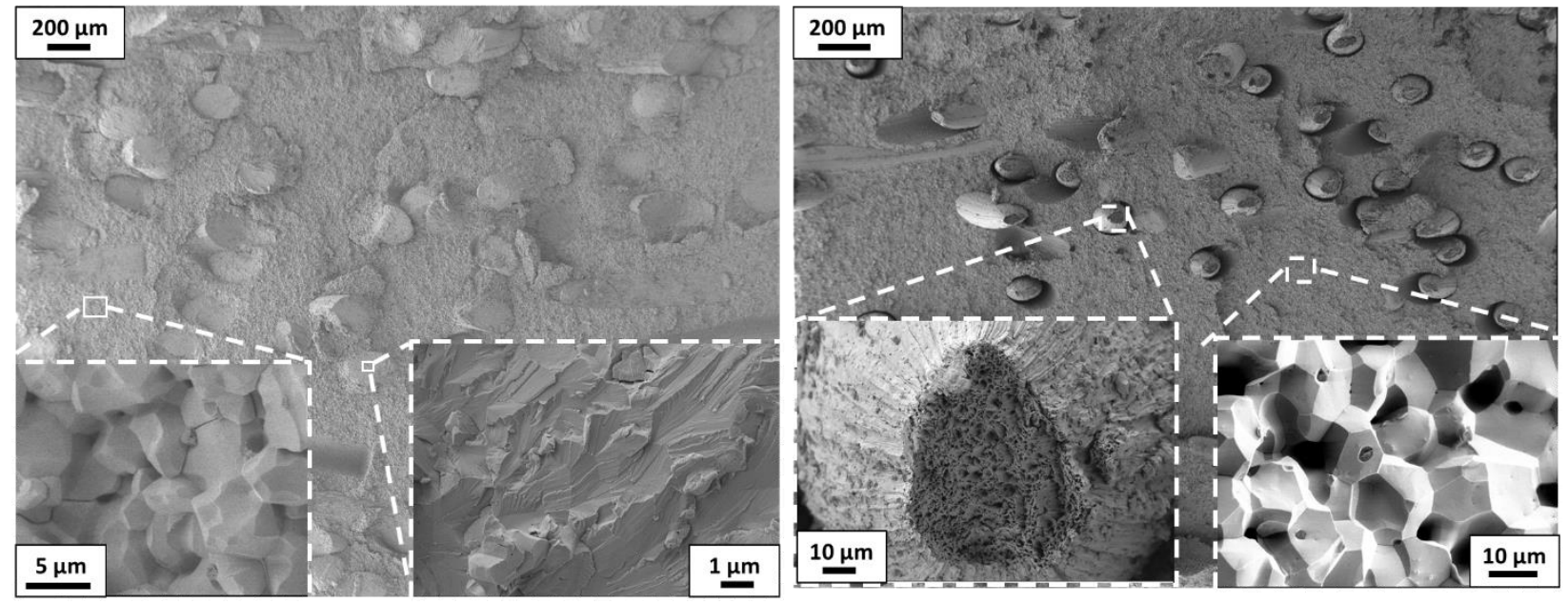

Figure 6 crack section after Charpy impact test for $\mathrm{W}_{\mathrm{f}} / \mathrm{W}$ samples measured at room temperature (left) and $1000{ }^{\circ} \mathrm{C}$ (right)

Based on the test results, the Charpy impact testing may not be a suitable experiment to characterize the fracture properties for $\mathrm{W}_{\mathrm{f}} / \mathrm{W}$. In case of the $\mathrm{W}_{\mathrm{f}} / \mathrm{W}$ material, fiber reinforcement mechanisms, like crack bridging, interface debonding, and fiber pull-out seem not effective at such 
a small time scale. High-velocity impact response is dominated by stress wave propagation through the material, in which the structure does not have sufficient time to respond, leading to very localized damage [27]. The material fractures without activating any extrinsic mechanisms. Even though the tungsten fibers appear to be highly ductile at $1000{ }^{\circ} \mathrm{C}$ (c.f. Figure 6 right), without ductility of the tungsten matrix, the influence of the tungsten fibers on the composite impact energy is quite limited. Comparable results are also found in experiments with CVD produced $\mathrm{W}_{\mathrm{f}} / \mathrm{W}$, showing that without the ductility of the matrix, a high impact energy could not be established [35].

\subsection{3-point bending test}

\subsubsection{Fracture behavior observation}

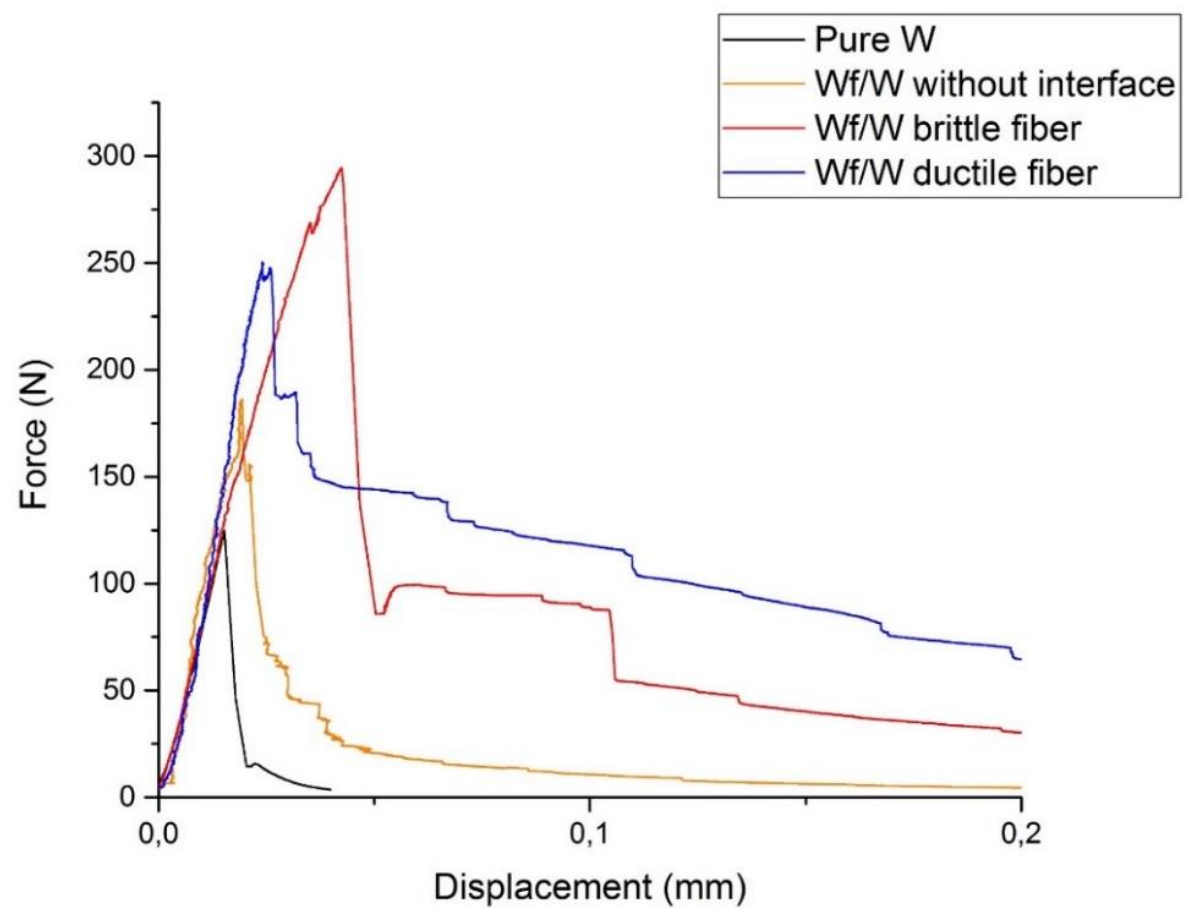

Figure 7 the typical force displacement curves of 3-point bending test on KLST samples. The W and Wf/W material are produced by FAST process. 
To avoid high strain rates as in the Charpy tests, a slower speed 3-point bending test is performed with an in-situ optical camera system. Typical force displacement curves for various types of samples are shown in Figure 7. Here, the sample named ' $W_{f} / W$ brittle fiber' and ' $W_{f} / W$ ductile fiber' means the $\mathrm{W}_{\mathrm{f}} / \mathrm{W}$ is produced with graphite sheets and tungsten sheets.

From Figure 7, it can be seen that, for $\mathrm{W}_{\mathrm{f}} / \mathrm{W}$ material, the force-displacement curves measured by the quantitative 3-point bending system give the same trend as the qualitative 3-point bending results in previous studies [5, 7]: after an increasing linear-elastic response, the slope of the load deflection curve changes slightly; then the load further increases with several small load drops; then a massive load-drop occurs after reaching the maximum load; afterwards, the samples tend to have a stepwise or continuous load-drop instead of a complete failure. On the other hand, pure tungsten and no-interface $\mathrm{W}_{\mathrm{f}} / \mathrm{W}$ only show linear-elastic deformation followed by catastrophic failure indicating merely a brittle fracture.

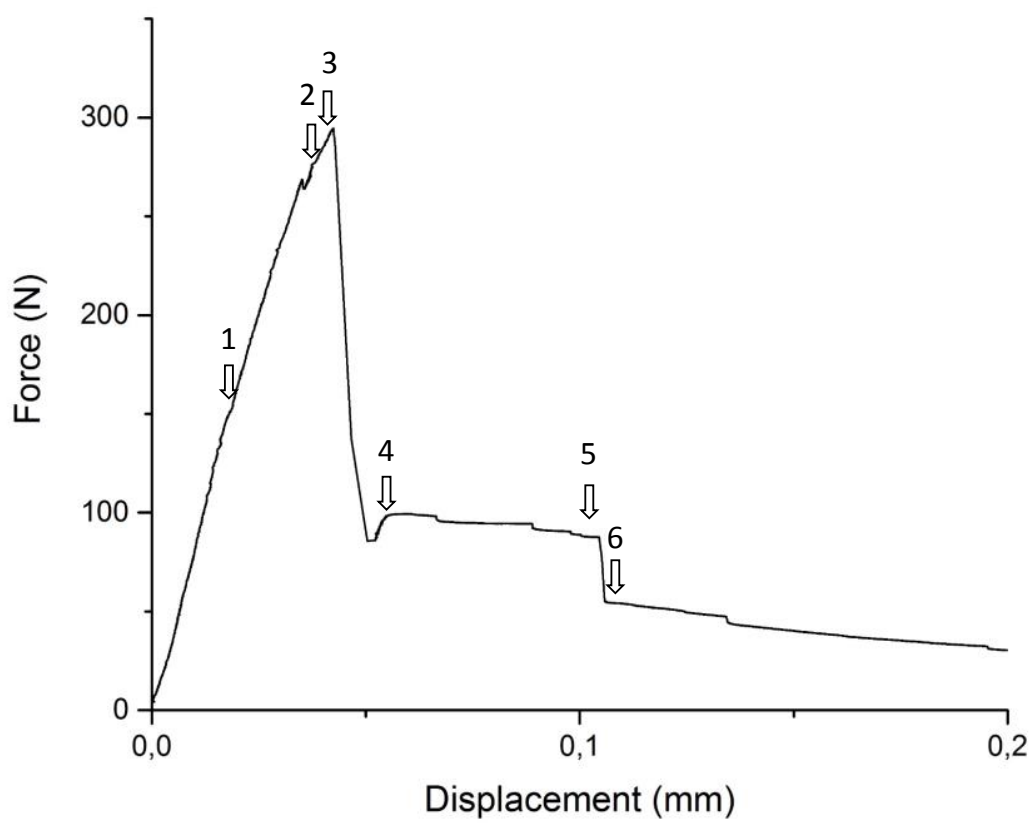

Figure 8 force displacement curve of the quantitative 3-point bending test; the arrows correspond to the tracked images in Figure 10. 


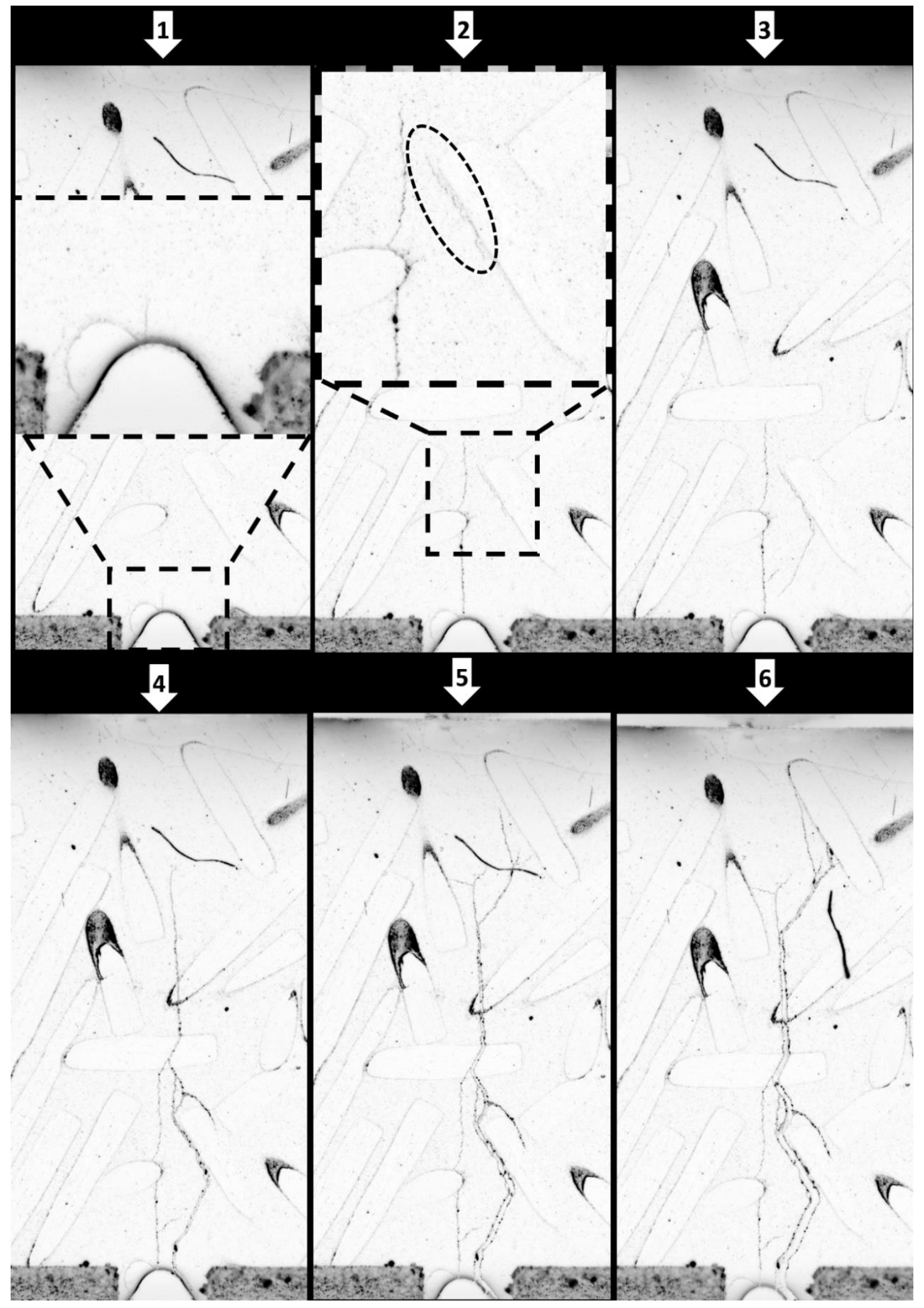

Figure 9 tracked images during the quantitative 3 point bending test 
For a detailed characterization of cracking propagation in FAST produced $\mathrm{W}_{\mathrm{f}} / \mathrm{W}$ composites, a single typical cracking process is studied in detail. The related force-displacement curve and the corresponding crack tracking images analyze six subsequent steps, as shown in Figure 8 and Figure 9.

For this sample, crack initiation begins upon reaching a force of $150 \mathrm{~N}$ (point 1 in Figure 8 and Figure 9). With increasing force, stable crack propagation occurs until $300 \mathrm{~N}$ load is reached (point 3 in Figure 8 and Figure 9). This stable crack opening is most likely established due to gradual interface debonding [36]. We observe the crack moving around the fiber in step 2 in Figure 9, which is evidence of crack deflection by the tungsten fiber. Moreover, in this image, a secondary crack initiation point (marked by a dotted ellipse) can be identified. This secondary crack initiation happens at the interface position of a fiber with a small relative angle to the primary crack direction. This kind of interface, during the bending test, is directly subjected to a high tensile load. When the local stress reaches the critical interface strength, secondary crack initiation can occur as predamage existing in the composite before the primary crack propagates through. From step 3 in Figure 9, a new crack becomes visible at the pre-damaged position. Further crack propagation in the sample follows this new path and a sudden load drop occurs together with a massive matrix and fiber failure (point 4 in Figure 8 and Figure 9). This leads to an intermediate unstable crack propagation. A new stable crack propagation stage is observed between step 4 and 5 (Figure 8 and Figure 9) probably relying on interface debonding and frictional fiber pull-out as the total sample displacement is already quite large. Crack deflection can be observed, and multiple crack fronts develop. At step 5-6, the crack front intersects another interface position, and the crack connects with the pre-damaged weak interface resulting in another sudden load drop. It must be noted that, this observation directly visualizes crack propagation at the surface only, but it is likely that the 
mechanisms within the bulk are similar. This stepwise analysis allows a basic description of the crack mechanisms of the FAST-produced random fiber $\mathrm{W}_{\mathrm{f}} / \mathrm{W}$.

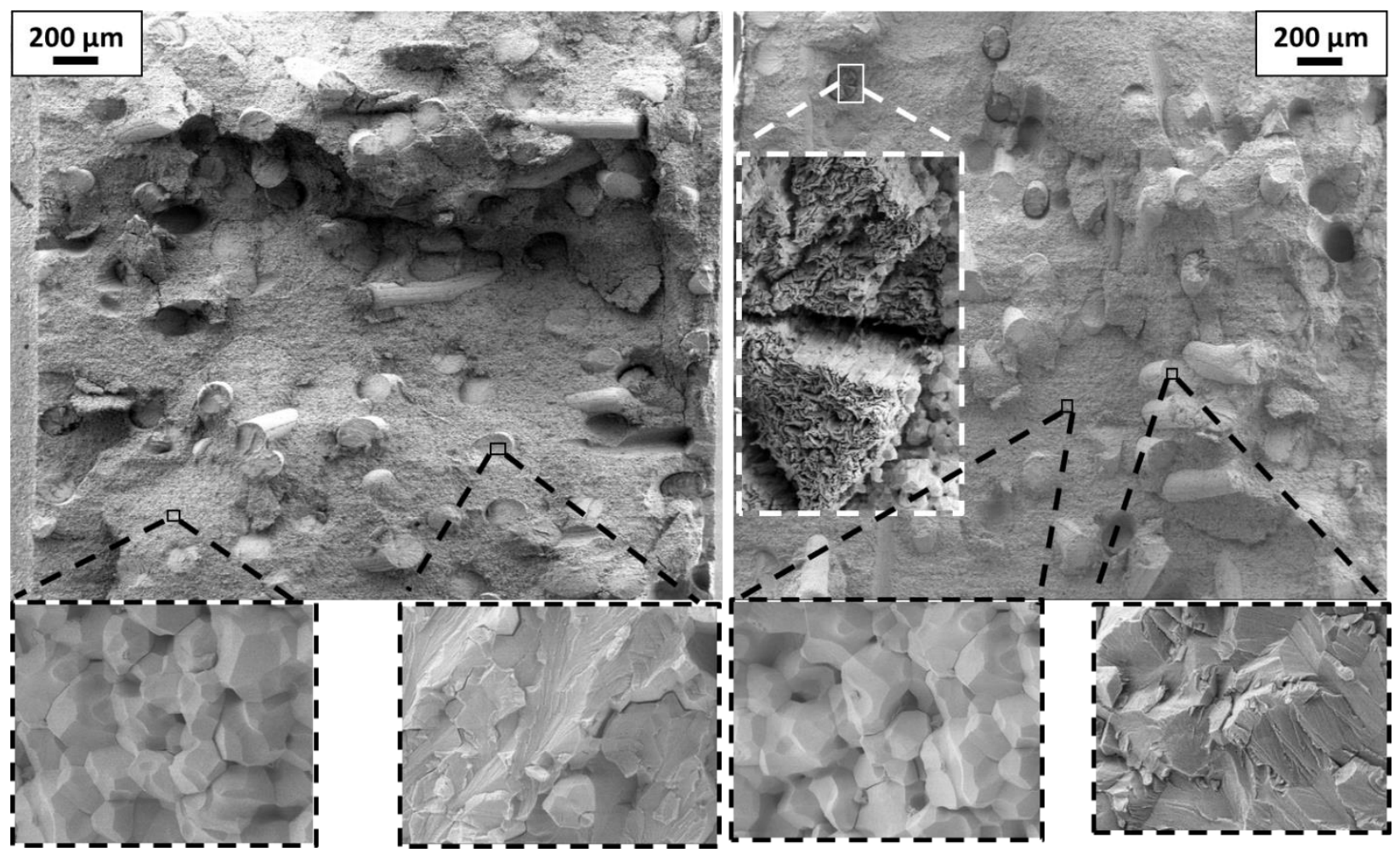

Figure 10 typical crack section after the quantitative 3-point bending test; a): $\mathrm{W}_{\mathrm{f}} / \mathrm{W}$ produced with graphite foil, $b$ ): $\mathrm{W}_{\mathrm{f}} / \mathrm{W}$ produced with tungsten foil. Pre-notch is on the left side of the image.

The typical fracture surface of the $\mathrm{W}_{\mathrm{f}} / \mathrm{W}$ after 3-point bending test is shown in Figure 10. On the fracture surface, crack deflection is indicated by the inhomogeneous topology of the surface. Also, fiber/matrix interface debonding is observed and some exposed fiber interfaces are clearly visible. Based on the above results and analysis, it can be confirmed that a pronounced pseudo-ductile fracture behavior is observed for $\mathrm{W}_{\mathrm{f}} / \mathrm{W}$ samples with a weak yttria interface $[8,37]$. Here fiber elastic bridging, interface debonding, crack deflection and fiber pull-out are likely the energy 
dissipation mechanisms that contribute to the elevated fracture resistance compared to pure tungsten.

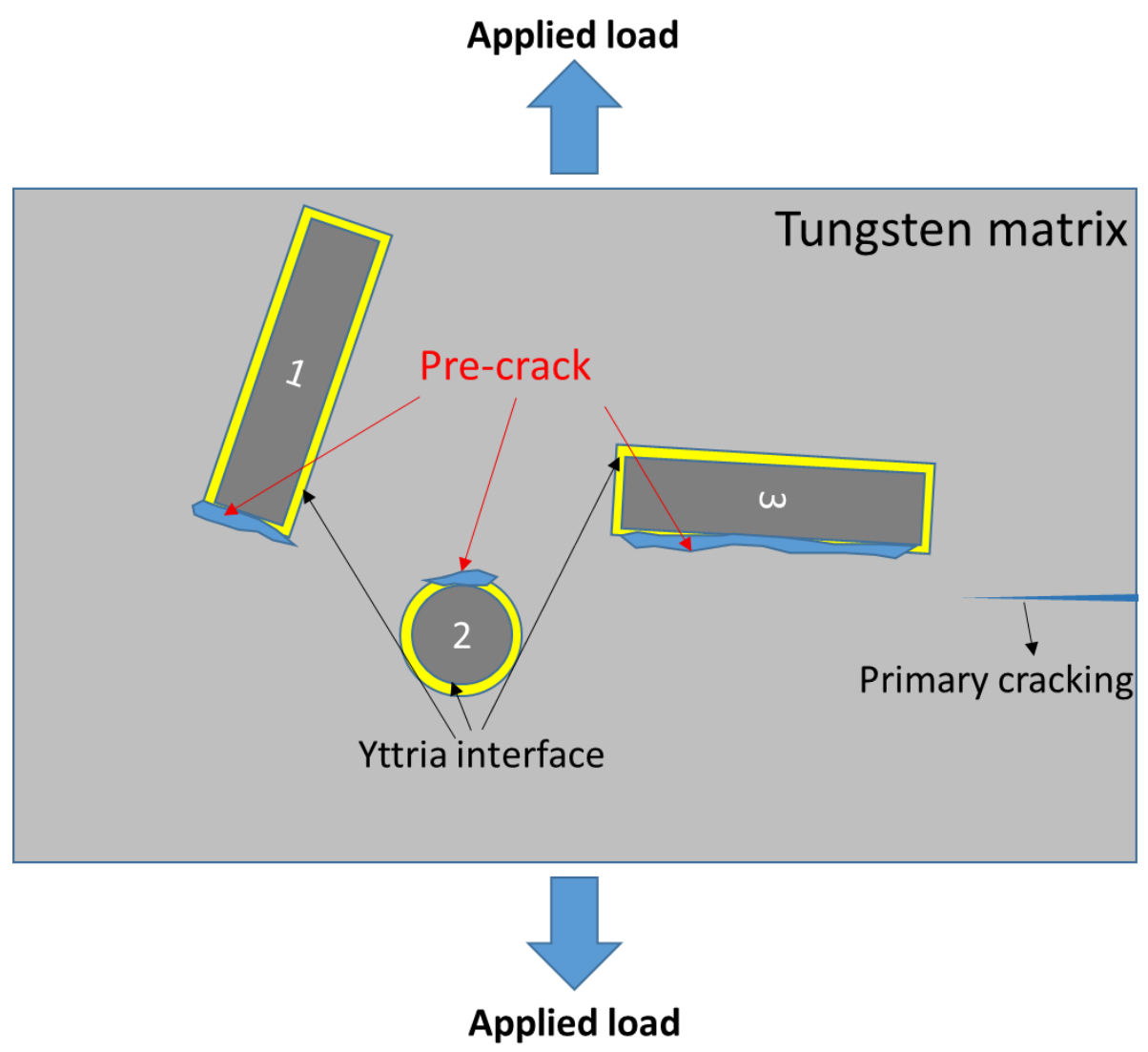

Figure 11 weak yttria interface failure under loading condition before matrix failure

However, for the randomly distributed short fiber $\mathrm{W}_{\mathrm{f}} / \mathrm{W}$ composite, unstable crack growth (massive load drop), is strongly influenced by the failure of the weak interface subjected to tensile forces. A schematic drawing of this secondary crack formation is shown in Figure 11. On the fracture surface, the exposed fiber interfaces represent the secondary crack initiation sites (predamage before matrix failure). From this point of view, the fracture behavior is affected by local fiber spatial and orientation distribution. Similar phenomenon in whisker-reinforced ceramic composites has occurred in previous study [38]. Compared to the previous results with CVD long fiber $\mathrm{W}_{\mathrm{f}} / \mathrm{W}[9,39]$, this is a unique mechanism. For aligned long fiber $\mathrm{W}_{\mathrm{f}} / \mathrm{W}$, no interface is directly 
subjected to a high tensile load, so the pre-damage before matrix failure cannot occur. For random fiber $\mathrm{W}_{\mathrm{f}} / \mathrm{W}$, the fiber ends in the composite could be another potential pre-damage source due to high shear stresses, as already discussed in [5], which also do not exist in long fiber $\mathrm{CVD} \mathrm{W}_{\mathrm{f}} / \mathrm{W}$ composite. For $\mathrm{CVD} \mathrm{W}_{\mathrm{f}} / \mathrm{W}$, unstable load drops during the test are mainly related to massive fiber failure [9].

What is also remarkable from Figure 10 (right) is that, even for the samples with reduced carbon contamination (tungsten foil protection during sintering), only few fibers show necking effect and the ductile knife edge pattern. The majority of the fibers show cleavage fracture surfaces. This could be caused by local strain rate differences during cracking. The fibers which break during unstable cracking may face larger strain rates. Such higher strain rates may inhibit ductile deformation of the tungsten fiber [40,41], similar to what was also observed in previous study [39].

\subsubsection{Fracture energy, fracture toughness and R-curves}

Based on the quantitatively measured force-displacement curves, fracture energies and fracture toughness values are calculated for various types of samples. The calculated values are shown in Table 2 and Table 3. The calculated R-curves are shown in Figure 12.

Table 2 measured fracture energy density based on 3-point bending test for different samples

\begin{tabular}{|c|c|c|c|c|}
\hline \multirow{2}{*}{ Samples } & \multicolumn{4}{|c|}{ Fracture energy density $\left(\mathrm{kJ} / \mathrm{m}^{2}\right)$} \\
\cline { 2 - 5 } & Test A & Test B & Test C & Test $\mathrm{D}$ \\
\hline Pure tungsten & 0.13 & 0.11 & - & - \\
\hline $\mathrm{W}_{\mathrm{f}} / \mathrm{W}$ without interface & 0.29 & 0.47 & - & - \\
\hline $\mathrm{W}_{\mathrm{f}} / \mathrm{W}$ (brittle fiber) & 2.4 & 1.6 & 1.1 & 2.3 \\
\hline $\mathrm{W}_{\mathrm{f}} / \mathrm{W}$ (ductile fiber) & 1.2 & 2.7 & - & - \\
\hline
\end{tabular}


Table 3 measured fracture toughness based on 3-point bending test for different samples

\begin{tabular}{|c|c|c|c|c|}
\hline \multirow{2}{*}{ Samples } & \multicolumn{4}{|c|}{ Fracture toughness $\mathrm{K}_{\mathrm{q}}\left(\mathrm{MPa} \mathrm{m}^{0.5}\right)$} \\
\cline { 2 - 5 } & Test $\mathrm{A}$ & Test B & Test C & Test D \\
\hline Pure tungsten & 5.48 & 5.62 & - & - \\
\hline $\mathrm{W}_{\mathrm{f}} / \mathrm{W}$ without interface & 8.17 & 20.41 & - & - \\
\hline $\mathrm{W}_{\mathrm{f}} / \mathrm{W}$ (brittle fiber) & 38.86 & 25.06 & 17.45 & 31.19 \\
\hline $\mathrm{W}_{\mathrm{f}} / \mathrm{W}$ (ductile fiber) & 22.06 & 20.34 & - & - \\
\hline
\end{tabular}

Based on the calculation results in Table 2 and Table 3, firstly, it is noticeable that, even for the same type of sample, the measured results are quite different. However, although the results show some scatter, we can still conclude that both fracture energy and fracture toughness of the weak interface $\mathrm{W}_{\mathrm{f}} / \mathrm{W}$ are much higher than those of the pure FAST tungsten. Additionally, the $\mathrm{W}_{\mathrm{f}} / \mathrm{W}$ without interface does not increase the tungsten toughness as efficiently as the with-interface case. For the R-curves, all the $\mathrm{W}_{\mathrm{f}} / \mathrm{W}$ samples with yttria interface and no-interface $\mathrm{W}_{\mathrm{f}} / \mathrm{W}$ sample $\mathrm{A}$ exhibit rising slopes. This means, for further crack opening, the crack driving force needs to be increased. The R-curve could not be measured for pure tungsten samples and no-interface sample B, because with the current experimental condition, a stable crack opening was not realized for these three samples. 


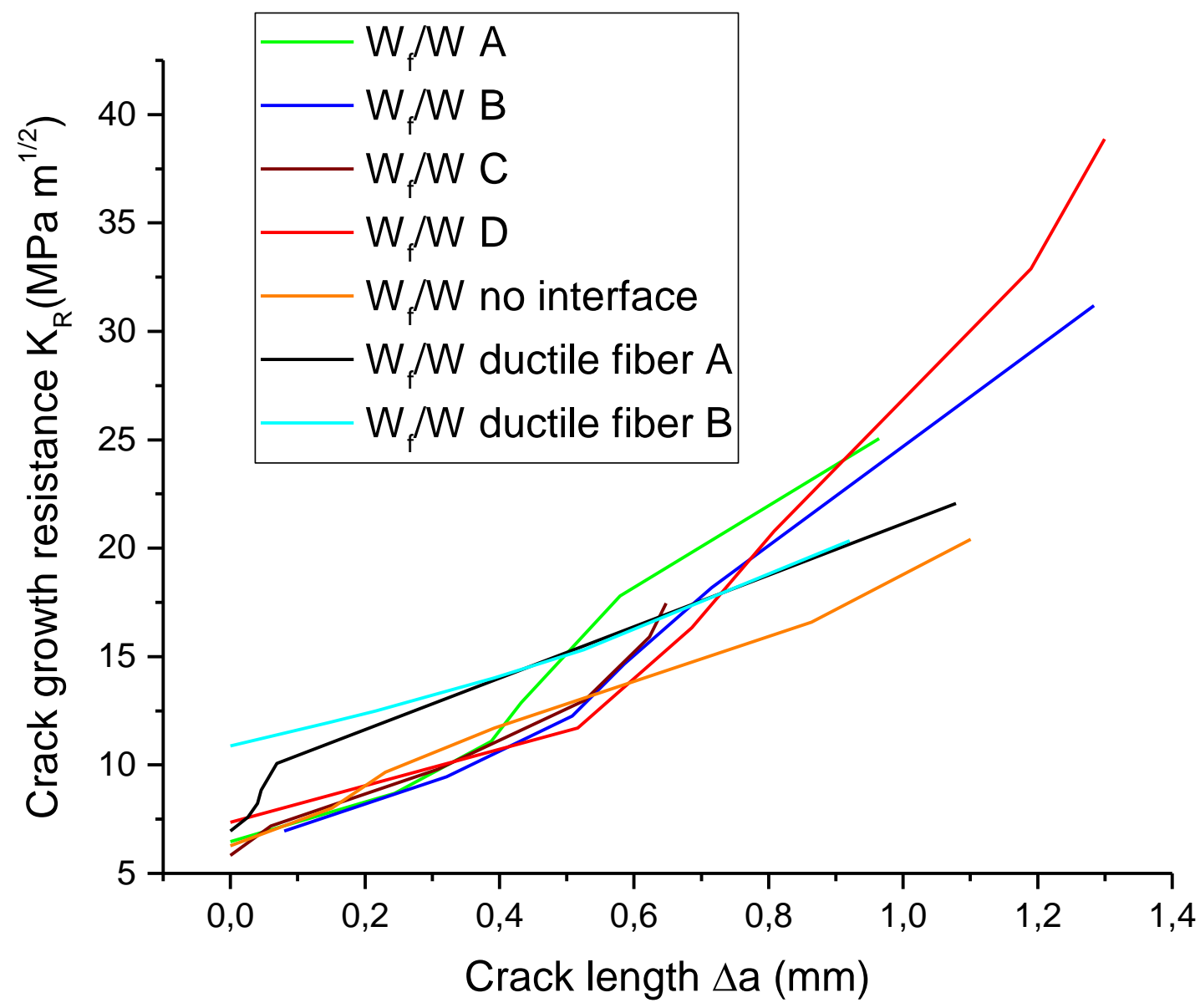

Figure 12 fracture resistance curves (R-curve) for $\mathrm{W}_{\mathrm{f}} / \mathrm{W}$ material

About the fracture energy, compared to pure tungsten, the additional energy dissipation is caused by the extrinsic toughening mechanisms. With the help of high strength tungsten fibers, the maximum composite load is higher for the $\mathrm{W}_{\mathrm{f}} / \mathrm{W}$. What is also important is the large displacement that contributes significantly to the energy absorption.

Regarding the fracture toughness and R-curves with rising slopes, between matrix failure until the maximum load, the crack grows stably with an increasing load based on the discussion in section 3.3.1 (c.f. Figure 8 and Figure 9). High fracture toughness relies on this stable crack growth capability. Within the stable crack growth region, the working space of the material is also 
increased. At RT, the fracture toughness of $\mathrm{W}_{\mathrm{f}} / \mathrm{W}$ material is comparable to cold rolled tungsten plates with relatively low degree of deformation [42].

Based on all the above results, the composite provides a much larger tolerance even after matrix failure. This is a clear signal towards improved defect tolerance.

We note that for the same type of sample, the measured results are quite scattered in terms of fracture energy and fracture toughness. This exposes a problem of the above tests, which is the specimen size limitation. With such small sample volume, the effect of an individual fiber is significant, which is influenced by the local fiber distribution. The composite material, hence, cannot be treated as a homogeneous material. In the future, to improve these data, a larger sample volume would be required, or a much smaller fiber diameter should be considered. In addition, to have a reliable quantitative measurement on such brittle based material, Weibull statistical methods may be required in future studies.

\section{Conclusion and Outlook}

In this work, field assisted sintering technology (FAST) is used to produce a $\mathrm{W}_{\mathrm{f}} / \mathrm{W}$ short-fiber composite. After sample production, a series of mechanical tests are performed to understand the fracture behavior of the material. Based on the mechanical characterization, the following conclusion can be drawn:

1. By introducing randomly distributed short tungsten fibers and a relatively weak yttria fiber/matrix interface, typical pseudo ductile fracture behavior can be established for $\mathrm{W}_{\mathrm{f}} / \mathrm{W}$ composite.

2. However, the local spatial and orientation distribution largely influence the crack behavior. This is a unique issue for $\mathrm{W}_{\mathrm{f}} / \mathrm{W}$ with randomly distributed fibers. 
3. The deformation rate of Charpy impact test is too high to establish a suitable test for $\mathrm{W}_{\mathrm{f}} / \mathrm{W}$. Under Charpy test condition, the FAST produced W matrix is still brittle at $1000{ }^{\circ} \mathrm{C}$.

4. Both fracture energies and fracture toughness values of $\mathrm{W}_{\mathrm{f}} / \mathrm{W}$ are much higher than that for pure tungsten. Based on the crack growth resistance curves (R-curves), $\mathrm{W}_{\mathrm{f}} / \mathrm{W}$ can establish a stable crack opening with continuously increasing load indicating improved defect tolerance.

Currently the conclusion is drawn based on limited number of tests. To obtain proper Weibull statistics, larger number of samples need to be tested. Also larger sample volumes should be used in the future to avoid the influence of the local fiber distribution.

\section{Acknowledgements}

This work has been carried out within the framework of the EUROfusion Consortium and has received funding from the Euratom research and training program 2014-2018 under grant agreement No. 633053. The views and opinions expressed herein do not necessarily reflect those of the European Commission.

\section{Reference}

[1] Philipps V. Tungsten as material for plasma-facing components in fusion devices. J Nucl Mater. 2011;415(1):S2-S9.

[2] Coenen JW, Antusch S, Aumann M, Biel W, Du J, Engels J, et al. Materials for DEMO and reactor applications - boundary conditions and new concepts. Physica Scripta. 2016;2016(T167):014002. 
[3] Smid I, Akiba M, Vieider G, Plöchl L. Development of tungsten armor and bonding to copper for plasma-interactive components. J Nucl Mater. 1998;258-263(Part 1):160-72.

[4] Pintsuk G, Bobin-Vastra I, Constans S, Gavila P, Rödig M, Riccardi B. Qualification and post-mortem characterization of tungsten mock-ups exposed to cyclic high heat flux loading. Fusion Engineering and Design. 2013;88(9-10):1858-61.

[5] Mao Y, Coenen JW, Riesch J, Sistla S, Almanstotter J, Jasper B, et al. Influence of the interface strength on the mechanical properties of discontinuous tungsten fiber-reinforced tungsten composites produced by field assisted sintering technology. Compos Part a-Appl S. 2018;107:342-53.

[6] Coenen JW, Mao Y, Sistla S, Riesch J, Hoeschen T, Broeckmann C, et al. Improved pseudoductile behavior of powder metallurgical tungsten short fiber-reinforced tungsten ( Wf / W ). Nuclear Materials and Energy. 2018;15:214-9.

[7] Mao Y, Coenen JW, Riesch J, Sistla S, Almanstötter J, Jasper B, et al. Development and characterization of powder metallurgically produced discontinuous tungsten fiber reinforced tungsten composites. Physica Scripta. 2017;T170:014005.

[8] Riesch J, Buffiere JY, Höschen T, di Michiel M, Scheel M, Linsmeier C, et al. In situ synchrotron tomography estimation of toughening effect by semi-ductile fibre reinforcement in a tungsten-fibre-reinforced tungsten composite system. Acta Materialia. 2013;61(19):7060-71.

[9] Gietl H, Riesch J, Coenen JW, Hoschen T, Linsmeier C, Neu R. Tensile deformation behavior of tungsten fibre-reinforced tungsten composite specimens in as-fabricated state. Fusion Engineering And Design. 2017;124:396-400. 
[10] Riesch J, Han Y, Almanstotter J, Coenen JW, Hoschen T, Jasper B, et al. Development of tungsten fibre-reinforced tungsten composites towards their use in DEMO-potassium doped tungsten wire. Physica Scripta. 2016;T167(T167):014006.

[11] Riesch J, Hoschen T, Linsmeier C, Wurster S, You JH. Enhanced toughness and stable crack propagation in a novel tungsten fibre-reinforced tungsten composite produced by chemical vapour infiltration. Physica Scripta. 2014;T159:014031.

[12] Neu R, Riesch J, Coenen JW, Brinkmann J, Calvo A, Elgeti S, et al. Advanced tungsten materials for plasma-facing components of DEMO and fusion power plants. Fusion Engineering and Design. 2016;109-111:1046-52.

[13] Du J, Höschen T, Rasinski M, Wurster S, Grosinger W, You JH. Feasibility study of a tungsten wire-reinforced tungsten matrix composite with ZrOx interfacial coatings. Composites Science and Technology. 2010;70(10):1482-9.

[14] Coenen JW, Mao Y, Almanstotter J, Calvo A, Sistla S, Gietl H, et al. Advanced materials for a damage resilient divertor concept for DEMO: Powder-metallurgical tungsten-fibre reinforced tungsten. Fusion Engineering And Design. 2017;124:964-8.

[15] Arzt E, Ashby MF, Easterling KE. Practical applications of hotisostatic Pressing diagrams: Four case studies. Metallurgical Transactions A. 1983;14(1):211-21.

[16] Orrù R, Licheri R, Locci AM, Cincotti A, Cao G. Consolidation/synthesis of materials by electric current activated/assisted sintering. Materials Science and Engineering: R: Reports. 2009;63(4-6):127-287.

[17] Czél G, Wisnom MR. Demonstration of pseudo-ductility in high performance glass/epoxy composites by hybridisation with thin-ply carbon prepreg. Composites Part A: Applied Science and Manufacturing. 2013;52:23-30. 
[18] Ming-Yuan H, Hutchinson JW. Crack deflection at an interface between dissimilar elastic materials. International Journal of Solids and Structures. 1989;25(9):1053-67.

[19] Zhao P, Riesch J, Hoschen T, Almanstotter J, Balden M, Coenen JW, et al. Microstructure, mechanical behaviour and fracture of pure tungsten wire after different heat treatments. Int J Refract Met H. 2017;68:29-40.

[20] Bewlay BP, Briant CL. The formation and the role of potassium bubbles in NS-doped tungsten. International Journal of Refractory Metals and Hard Materials. 1995;13(1):137-59. [21] Müller A, Ilg M, Gietl H, Höschen T, Neu R, Pintsuk G, et al. The effects of heat treatment at temperatures of $1100^{\circ} \mathrm{C}$ to $1300{ }^{\circ} \mathrm{C}$ on the tensile properties of high-strength drawn tungsten fibres. Nuclear Materials and Energy. 2018;16:163-7.

[22] Ohser-Wiedemann R, Martin U, Müller A. Fast sintering of mechanical alloyed Mo-W powders. Proceedings of the International Euro Powder Metallurgy Congress and Exhibition, Euro PM 20122012.

[23] Chanthapan S, Kulkarni A, Singh J, Haines C, Kapoor D. Sintering of tungsten powder with and without tungsten carbide additive by field assisted sintering technology. International Journal of Refractory Metals and Hard Materials. 2012;31:114-20.

[24] Cho KC, Woodman RH, Klotz BR, Dowding RJ. Plasma pressure compaction of tungsten powders. Materials and Manufacturing Processes. 2004;19(4):619-30.

[25] Rieth M, Hoffmann A. Influence of microstructure and notch fabrication on impact bending properties of tungsten materials. International Journal of Refractory Metals and Hard Materials. 2010;28(6):679-86.

[26] Prüfung metallischer Werkstoffe; Kerbschlagbiegeversuch; Besondere Probenform und Auswertungsverfahren. s.1. DIN 50115: Beuth-Verlag; 1991. 
[27] Richardson MOW, Wisheart MJ. Review of low-velocity impact properties of composite materials. Composites Part A: Applied Science and Manufacturing. 1996;27(12):1123-31. [28] Reiser J, Wurster S, Hoffmann J, Bonk S, Bonnekoh C, Kiener D, et al. Ductilisation of tungsten (W) through cold-rolling: R-curve behaviour. International Journal of Refractory Metals and Hard Materials. 2016;58:22-33.

[29] Gilbert CJ, Cao JJ, Jonghe LC, Ritchie RO. Crack-Growth Resistance-Curve Behavior in Silicon Carbide: Small versus Long Cracks. J Am Ceram Soc. 2005;80(9):2253-61.

[30] Chabanet O, Steglich D, Besson J, Heitmann V, Hellmann D, Brocks W. Predicting crack growth resistance of aluminium sheets. Computational Materials Science. 2003;26:1-12. [31] Banthia N, Nandakumar N. Crack growth resistance of hybrid fiber reinforced cement composites. Cement and Concrete Composites. 2003;25(1):3-9.

[32] Sen D, Buehler MJ. Structural hierarchies define toughness and defect-tolerance despite simple and mechanically inferior brittle building blocks. Scientific reports. 2011;1:35. [33] Mao Y, Engels J, Houben A, Rasinski M, Steffens J, Terra A, et al. The influence of annealing on yttrium oxide thin film deposited by reactive magnetron sputtering: Process and microstructure. Nuclear Materials and Energy. 2017;10:1-8.

[34] Jasper B, Schoenen S, Du J, Hoeschen T, Koch F, Linsmeier C, et al. Behavior of tungsten fiber-reinforced tungsten based on single fiber push-out study. Nuclear Materials And Energy. 2016;9:416-21.

[35] Riesch J, Aumann M, Coenen JW, Gietl H, Holzner G, Höschen T, et al. Chemically deposited tungsten fibre-reinforced tungsten - The way to a mock-up for divertor applications. Nuclear Materials and Energy. 2016;9:75-83.

[36] Kim J-K, Mai Y-W. Engineered interfaces in fiber reinforced composites: Elsevier; 1998. 
[37] Stang H, Shah SP. Failure of fibre-reinforced composites by pull-out fracture. Journal of Materials Science. 1986;21(3):953-7.

[38] Becher PF, Hsueh CH, Angelini P, Tiegs TN. Toughening Behavior in Whisker - Reinforced Ceramic Matrix Composites. J Am Ceram Soc. 1988;71(12):1050-61.

[39] Neu R, Riesch J, Müller Av, Balden M, Coenen JW, Gietl H, et al. Tungsten fibre-reinforced composites for advanced plasma facing components. Nuclear Materials and Energy. 2017;12:1308-13.

[40] Rupp D, Weygand SM. Loading rate dependence of the fracture toughness of polycrystalline tungsten. J Nucl Mater. 2011;417(1):477-80.

[41] Giannattasio A, Roberts SG. Strain-rate dependence of the brittle-to-ductile transition temperature in tungsten. Philos Mag. 2007;87(17):2589-98.

[42] Bonnekoh C, Hoffmann A, Reiser J. The brittle-to-ductile transition in cold rolled tungsten: On the decrease of the brittle-to-ductile transition by $600 \mathrm{~K}$ to $-65^{\circ} \mathrm{C}$. International Journal of Refractory Metals and Hard Materials. 2018;71:181-9. 